(2) Open Access Full Text Article

REVIEW

\title{
Assessing the role of the EGF receptor in the development and progression of pancreatic cancer
}

\author{
Natalie Cook' \\ Kristopher K Frese ${ }^{2}$ \\ Malcolm Moore' \\ 'Division of Medical Oncology \\ and Hematology, ${ }^{2}$ Ontario Cancer \\ Institute, Princess Margaret Cancer \\ Centre, Toronto, ON, Canada
}

This article was published in the following Dove Press journal:

Gastrointestinal Cancer:Targets and Therapy

2 April 2014

Number of times this article has been viewed

\begin{abstract}
The prognosis for patients with pancreatic cancer remains poor despite increased knowledge of its molecular genetics and histopathological progression. Pancreatic cancer is a complicated, heterogeneous tumor with several common genetic alterations. Aberrant epidermal growth factor receptor (EGFR) expression can be found in chronic pancreatitis and in preinvasive and invasive pancreatic cancer. Therefore targeting this receptor, through monoclonal antibodies or downstream inhibition of tyrosine kinase activity, has the potential to produce encouraging results. Despite this, the majority of targeted therapies against EGFR have not performed as expected in clinical trials of pancreatic cancer. Understanding mechanisms of resistance and identification of pertinent biomarkers of efficacy will likely lead to further optimization of EGFR-directed treatment. In this article, we discuss the role of EGFR in the development and progression of pancreatic cancer, mechanisms of action of EGFR-directed agents, and the future of epidermal growth factor targeted-therapy and research in pancreatic cancer.
\end{abstract}

Keywords: epidermal growth factor receptor, therapies, resistance

\section{Introduction}

Pancreatic cancer is one of the most lethal human cancers because of late presentation, early metastases, and resistance of tumor cells to conventional treatments, such as radiation and chemotherapy. It is the fourth most common cause of cancer deaths in the USA, with dismal 5-year survival rates of less than 5\% that have remained largely unchanged for several decades. ${ }^{1}$ Substantial efforts to understand the molecular genetics of pancreatic cancer have identified several common mutations and a plethora of less common genetic alterations. ${ }^{2}$ The average pancreatic cancer genome contains approximately one mutation per megabase, revealing it to be a complicated heterogeneous tumor. ${ }^{3}$ A thorough understanding of this genetic complexity is essential to even begin to comprehend the interactions of the multiple signaling cascades that are involved in the initiation and maintenance of this cancer.

Increased knowledge of the genetic and molecular nature of cancer aids us in developing agents that can specifically target these abnormalities. The epidermal growth factor receptor family of receptor tyrosine kinases (RTKs) includes the epidermal growth factor receptor (EGFR) HER1 (also known as ErbB1), HER2 (also known as Neu/ErbB2), HER3 (also known as ErbB3), and HER4 (also known as ErbB4) receptors. These transmembrane glycoproteins are activated by ligands, expressed in many cell types, and have a diverse role in normal cell proliferation and differentiation. ErbB family members are overexpressed or mutated in many different types of cancer, including pancreatic cancer. ${ }^{4}$ EGFR is also overexpressed in chronic pancreatitis,
Correspondence: Malcolm Moore Division of Medical Oncology and Hematology, Princess Margaret Cancer Centre, Toronto, Ontario, Canada

Tel +l 4169462263

Fax + I 4169462082

Email malcolm.moore@uhn.ca 
a risk factor for pancreatic cancer. Due to its varied role in the development, growth, and survival of cancer cells, it has been actively pursued as an anticancer therapy, ${ }^{5}$ and there are now multiple antibodies and small molecular tyrosine kinase inhibitors available that target EGFR.

This review aims to assess the role the EGFR family has in the development and progression of pancreatic cancer. It explores the research that has been performed thus far, both preclinically and clinically, and considers the impact EGFR has had on the treatment and understanding of pancreatic cancer. However, before embarking on EGFR and pancreatic cancer, it is important to first understand the development, genetics, and treatment of pancreatic cancer and the role that the EGFR family plays in cancer in general.

\section{Pancreatic cancer Development and genetics of pancreatic cancer}

Pancreatic ductal adenocarcinoma (PDA) is the most common type of pancreatic cancer, presumably arising from the exocrine part of the pancreas. To date there have been multiple precursor lesions identified, including mucinous cystic neoplasia, intraductal papillary mucinous neoplasia, ${ }^{6}$ and pancreatic intraepithelial neoplasia (PanIN). PanIN are perhaps the best characterized histological precursor to PDA and are common findings from autopsy studies in adults. ${ }^{7}$ Chronic pancreatitis has also been linked to the development of pancreatic cancer. Both molecular genetics and mouse models of pancreatic cancer suggest that acinar to ductal metaplasia (ADM) is a precursor to the development of the earliest stage of PanINs. ${ }^{8,9}$

Despite the few proven therapeutic options available for the treatment of pancreatic cancer, intensive characterization of its molecular genetics has clarified the spectrum of mutations present within the disease. ${ }^{10}$ A comprehensive genetic analysis of 24 human PDAs revealed that, on average, a mature pancreatic cancer cell contains 63 genetic alterations per cancer exome. These can then be grouped into 12 core signaling pathways. ${ }^{2}$ Among the most common alterations in PDA are activating mutations in the KRAS proto-oncogene. Such mutations are found in almost $95 \%$ of human cases and have the effect of impairing the ability of $K R A S$ to hydrolyze guanosine triphosphate (GTP) to guanosine diphosphate (GDP), effectively locking the KRAS protein in an active signaling conformation. ${ }^{11}$ This causes constitutive signaling to classical effector pathways, Raf, PI3 Kinase, and RalGDS, in the absence of exogenous growth factors. ${ }^{12}$ The second commonest alterations are inactivating mutations in the $p 16 I N K 4 a$ gene $(90 \%$ of cases). ${ }^{13}$ Other common alterations include mutation of TP53 (approximately $75 \%$ of cases), SMAD4 (55\%), and BRCA2 $(10 \%) \cdot{ }^{13-15}$ These alterations result in several of the hallmarks of cancer, including bypass of DNA-damage checkpoints, avoidance of apoptotic signals, induction of genomic instability, and activation of aberrant signal transduction. These genetic changes accumulate and are found with increasing frequency in higher grade PanIN lesions. This has led to the understanding that $K R A S$ and $I N K 4 A$ alterations are early events in PDA development, while loss or mutation of SMAD4 and p53 tend to occur later. ${ }^{16}$

\section{EGFR}

\section{HER family signaling}

The EGFR family consists of four RTKs, which we will refer to in this article as EGFR, HER2, HER3, and HER4. Members of this family of receptors are expressed in many different cell types and play varied roles in development, proliferation, differentiation, and apoptosis. ${ }^{2}$ They can activate a variety of downstream pathways including the Ras/ mitogen-activating protein (MAP) kinase pathway, the PI3K/ protein kinase B (Akt) pathway, v-Src avian sarcoma viral oncogene homolog (Src) family kinases, and signal transducers and activator of transcription (STAT) proteins. ${ }^{17,18}$ This results in upregulation of mitogenic, antiapoptotic, angiogenic, and proinvasive cellular mechanisms. As these cellular processes are often deregulated in cancer, this can then promote unregulated growth stimulation and development of tumors, in cancer types including breast, lung, brain, colon, and pancreas. ${ }^{5}$

The EGFR is a classical RTK, for which ligand binding stabilizes the formation of receptor homo- or heterodimers within the plasma membrane. The seven known receptor dimer combinations and ten interacting ligands enable quite complicated signaling cascades (Figure 1). ${ }^{19}$ The HER4 receptor is structurally similar to EGFR and is capable of ligand-dependent homodimerization and heterodimerization. Conversely, HER2 receptors have no known direct ligand and have been shown to elicit both ligand-dependent and ligand-independent dimerization. ${ }^{20}$ HER3 receptors can undergo ligand-dependent dimerization; however these receptors lack a functional kinase domain and therefore require heterodimerization for active signal transduction. Autophosphorylation of one intracellular kinase domain by the other initiates cytoplasmic signal transduction cascades that can vary depending on the nature, duration, and context of receptor activation (Figure 2). Upon ligand binding, 


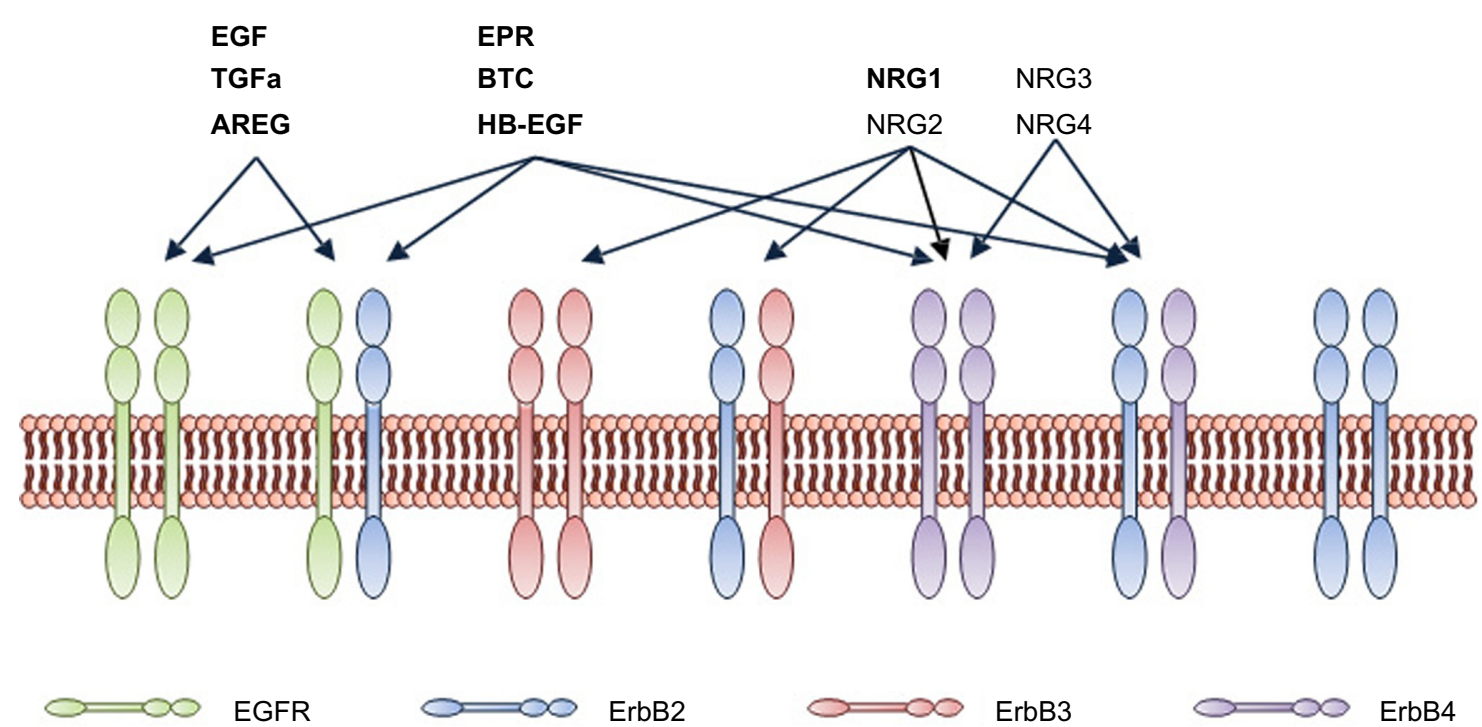

Figure I The EGFR family receptors and ligands.

Notes: The different EGFR dimers and their interacting ligands are shown. Bolded ligands are reported to be overexpressed in PanIN and/or pancreatic cancer. Note that ErbB2 homodimers can function in the absence of ligand.

Abbreviations: AREG, amphiregulin; BTC, betacellulin; EGF, epidermal growth factor; EGFR, epidermal growth factor receptor; EPR, epiregulin; ErbB2, v-erb-b2 avian erythroblastic leukemia viral oncogene homolog; HB-EGF, heparin-binding EGF-like growth factor; NRG, neuregulin; PanIN, pancreatic intraepithelial neoplasia;TGF, transforming growth factor.

receptors are internalized via receptor-mediated endocytosis, where they can then either be degraded, recycled back to the plasma membrane, or translocate to the nucleus via nuclear import proteins, such as importin-beta. ${ }^{21}$ Although studies on the role of nuclear EGFR are limited, this has been shown to interact with several transcription factors, including STAT3, STAT5A, E2F transcription factor 1 (E2F1), and DNA-dependent protein kinase (DNA-PK), ${ }^{22,23}$ and has been found to have an essential role in promoting DNA replication and repair. A more detailed discussion of the biology of the EGFR family, its relationship to different cancers, and anti-EGFR/ErbB therapies can be found in two excellent review articles. ${ }^{5,24}$

\section{Relevance of EGFR in cancer}

Inappropriate activation of EGFR in cancer can occur through a variety of different mechanisms, including overexpression, point mutations, partial deletions, liganddependent receptor dimerization, and ligand-independent activation. ${ }^{19}$ EGFR signaling is initiated at the cell membrane and transmitted to the nucleus via cytoplasmic intermediates. ${ }^{21}$ Interestingly EGFR and its family members have been consistently found in the nucleus of tumor specimens associated with a poor clinical prognosis in cancer types such as ovarian, oropharyngeal, lung, and breast cancer. ${ }^{25-29}$ EGFR has also been identified as a transcriptional coactivator for many cancer-promoting genes, including cyclin $D 1,{ }^{21}$ iNOS, ${ }^{22} C O X-2^{30}$ and $c-m y c .{ }^{31}$
In addition to the role EGFR signaling plays in tumor cells, it can also play an important role in the tumor microenvironment (TME). EGFR has been shown to be expressed in non-neoplastic cell types in the TME. It can stimulate the synthesis of a number of angiogenesis-related factors, including vascular endothelial growth factor (VEGF), interleukin-8, and basic fibroblast growth factor. ${ }^{32}$ Therefore EGFR signaling may play an important supportive role in tumor cell proliferation, angiogenesis, and metastasis. ${ }^{33}$

\section{Targeting EGFR in cancer}

Due to the frequent activation of the EGFR family members in cancer, there have been multiple small-molecule tyrosine kinase inhibitors (TKIs) and monoclonal antibodies developed against them, particularly the EGF and HER2 receptors (Figure 2). Small-molecule TKIs inhibit EGFR signaling by competing with adenosine-5' - triphosphate (ATP) for the intracellular tyrosine kinase domain of the receptor, thereby preventing the autophosphorylation and activation of signaling pathways downstream of EGFR. ${ }^{19}$ They can be reversible or irreversible and have the theoretical advantage of inhibiting ligand-independent activity of EGFR. The two best recognized EGFR-targeted TKIs used in the clinical treatment of patients are erlotinib and gefitinib. Several EGFR TKIs can block multiple members of the EGFR family; for example, lapatinib reversibly inhibits both HER2 and EGFR. Monoclonal antibodies against EGFR competitively bind the extracellular ligand-binding region of the receptor 


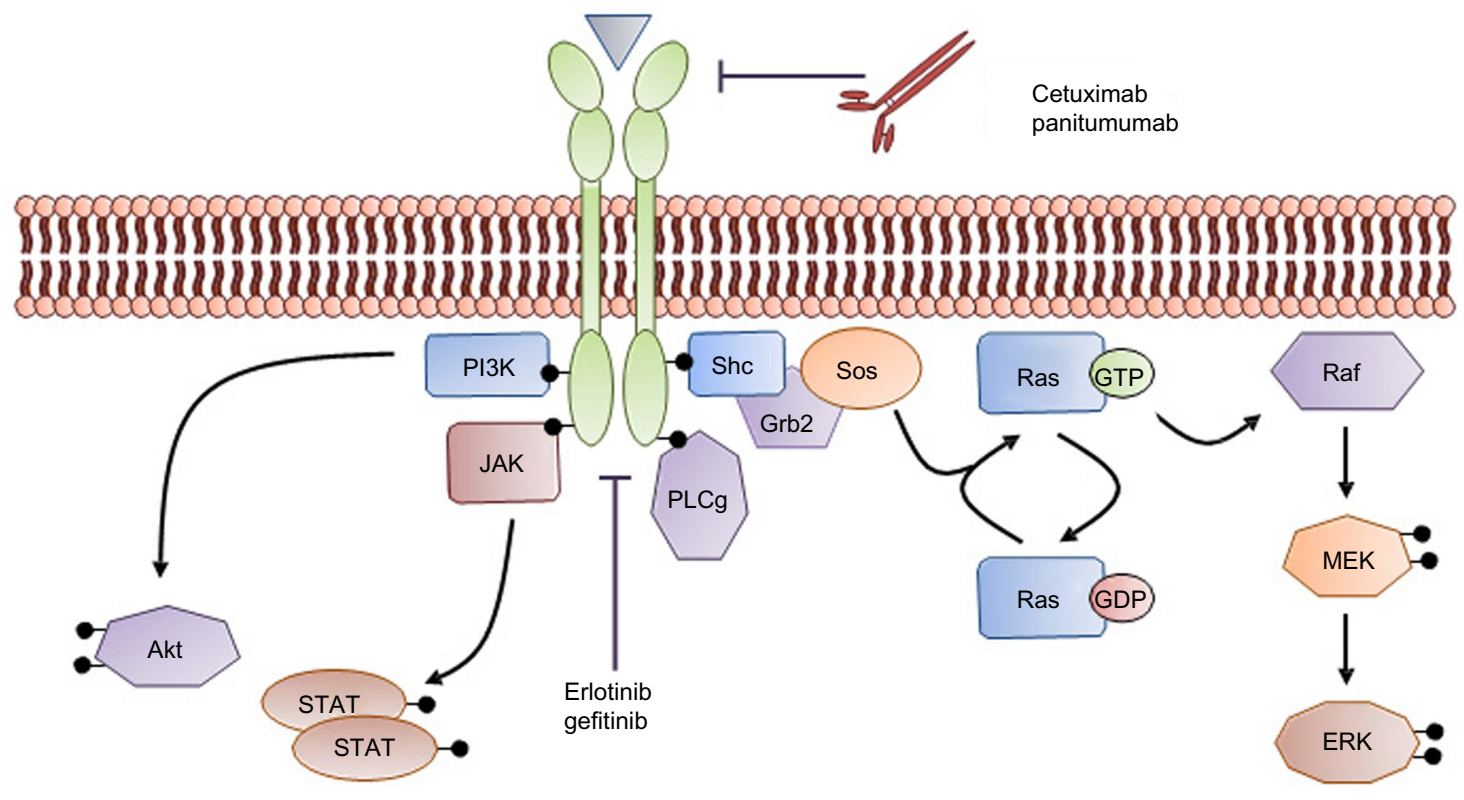

Figure 2 EGFR cytoplasmic signal transduction.

Notes: Upon dimerization, receptor phosphorylations serve as docking sites for several cytoplasmic signaling molecules. Those depicted are the best characterized but are not meant to be exhaustive. Therapeutics that target this pathway, including small-molecule tyrosine kinase inhibitors and antibodies, are also depicted.

Abbreviations: AKT, protein kinase B; EGFR, epidermal growth factor receptor; ERK, extracellular signal-regulated kinase; GDP, guanosine diphosphate; Grb2, growth factor receptor-bound protein 2; GTP, guanosine triphosphate; Jak, Janus kinase; Mek, mitogen-activated protein/extracellular signal-regulated kinase kinase; PI3K, phosphoinositide 3'-kinase; PLC, phospholipase C; Raf, rapidly accelerated fibrosarcoma; Ras, rat sarcoma; Shc, Src homology 2 domain-containing; Sos, son of sevenless homolog I; STAT, signal transducers and activator of transcription.

in its inactivated position. Once bound, they prevent ligand binding and receptor dimerization, therefore blocking endogenous ligand activation of EGFR in a highly specific way. ${ }^{34}$ Examples currently used in the clinical treatment of patients include cetuximab, an immunoglobulin $\mathrm{G}(\operatorname{IgG}) 1$ chimeric antibody, and panitumumab, a fully humanized IgG2 antibody. The most investigated anti-HER2 antibody is trastuzumab, the first monoclonal antibody to be approved by the US Food and Drug Administration (FDA) in 1998. ${ }^{35}$ In contrast, there are only a few agents that target HER 3 and HER4 that have thus far progressed to the clinic. Perhaps the most famous anti-HER4 agent in early stage trials currently is dacomitinib, an irreversible inhibitor of EGFR, HER2, and HER4. ${ }^{36}$

\section{EGFR and the development of pancreatic cancer}

Due to the difficulty of diagnosing PDA at an early stage, most of the research examining the effect of EGFR in the development of pancreatic cancer has been performed in cell culture or in preclinical mouse models. However, there are some immunohistochemical (IHC) studies that have managed to look at PDA-associated PanIN in surgical specimens. An early IHC analysis of PanIN lesions revealed HER 2 overexpression in over $80 \%$ of PanIN1a lesions. ${ }^{37}$ Subsequent studies in $\mathrm{KRAS}^{\mathrm{G} 12 \mathrm{D}}$-driven mouse models of pancreatic cancer demonstrated that EGFR and HER2 are frequently overexpressed in ADM and PanIN1a lesions, ${ }^{8,38}$ indicating that activation of the EGFR signaling axis is an early event in pancreatic carcinogenesis. The first direct evidence of a role for EGFR signaling in the development of pancreatic cancer came from transgenic mice overexpressing the EGF ligand transforming growth factor (TGF $\alpha$ ) in the pancreas. ${ }^{39,40}$ Metallothionein-TGF $\alpha$ and elastase-TGF $\alpha$ transgenic mice developed widespread acinar-ductal metaplasia by 3 months of age, and the additional knockout of p53 accelerated the development of carcinomas. ${ }^{41}$ Interestingly, mice expressing the EGF ligand amphiregulin from the elastase promoter displayed ductal cell hyperplasia rather than $\mathrm{ADM}$, indicating that not all EGF ligands behave similarly. Correspondingly, PanIN lesions in a murine model of pancreatic cancer expressed TGF $\alpha$, but not EGF. ${ }^{42}$ In vitro experiments utilizing acinar explants revealed that TGF $\alpha$-mediated EGFR activation promoted ADM via a Notch-dependent mechanism. ${ }^{43,44}$ Additionally, expression of KRAS ${ }^{\mathrm{G} 12 \mathrm{D}}$ promotes ADM both in vitro and in vivo, via an EGFR-dependent mechanism. More recently, two comprehensive studies demonstrated a requirement for EGFR in ADM and tumor formation in genetically engineered mouse models of pancreatic cancer. ${ }^{45,46}$ Deletion of 
EGFR prevented tumorigenesis in $\mathrm{KRAS}^{\mathrm{G} 12 \mathrm{D}}, \mathrm{CDKN}^{2} \mathrm{~A}^{\text {flox }}$ mice, but only delayed tumor formation in $\mathrm{KRAS}^{\mathrm{G} 12 \mathrm{D}}$, $\mathrm{p} 53^{\text {flox }}$ mice. Furthermore, EGFR had no effect on KRAS ${ }^{\mathrm{G} 12 \mathrm{D}}$-driven lung tumorigenesis. Together these data indicate that the efficacy of EGFR inhibition can vary, depending on genetic and tissue context.

\section{EGFR and the progression of pancreatic cancer}

The role for EGFR in tumor maintenance and progression is less clear; however, multiple studies have been published utilizing patient samples. Both receptors and ligands have been shown to be overexpressed in frank carcinomas; however, the relevance of these observations remains controversial. Experiments examining the effect of EGFR in cell lines have shown that cells can undergo cell cycle arrest, apoptosis, or remain indifferent, depending on the cell line and assay used. Despite numerous attempts to identify biomarkers predictive of response, there have been conflicting results regarding the predictive value of gene amplification, receptor overexpression, and receptor phosphorylation. The most systematic approach investigated the sensitivity of 639 human cancer cell lines, including 17 pancreatic lines, for sensitivity to erlotinib, gefitinib, afatinib, and lapatinib. ${ }^{47}$ Despite promising results, such as the association of lapatinib sensitivity with cell lines with either HER2 overexpression or mutation, there was no overlap of genes predicting sensitivity or resistance for all four inhibitors tested. The association that most closely approaches significance is the well-documented role for $K R A S / N R A S$ mutations in resistance to EGFR-targeted therapies. ${ }^{48}$ While these data may reflect the idiosyncrasies of each inhibitor, they nonetheless underscore the labyrinthine nature of biomarker discovery.

The use of genetically engineered mouse models and patient-derived xenografts are generally considered more representative of the human disease compared with cell lines and thus have been used to study disease progression and response to treatment. Although genetic ablation or therapeutic inhibition of EGFR can markedly reduce the initiation of pancreatic cancer in mice, treatment of radiographically-confirmed tumors with erlotinib alone or in combination with gemcitabine failed to extend survival. ${ }^{45}$ In a more promising study of pancreatic cancer patient-derived xenografts, six out of ten pancreatic tumor models exhibited a statistically significant, albeit modest growth inhibition by either erlotinib or cetuximab treatment, whereas two out of ten tumor models exhibited dramatic growth inhibition or regression by both agents. ${ }^{49}$
Consistent with clinical results, neither $K R A S$ status nor IHC-based assessment of the EGFR pathway could predict sensitivity; however, gene set enrichment analysis uncovered a transcriptional signature that successfully predicted the sensitivity of an independent set of xenografts to erlotinib.

The following sections focus on the known role of each EGFR family member in the progression of pancreatic cancer in human specimens.

\section{EGFR}

EGFR overexpression or amplification in advanced pancreatic cancer occurs in anywhere between $30 \%$ and $95 \%$ of cases examined. ${ }^{50-54}$ In one study, using tissue microarrays from PDA patients, EGFR expression was present in 49 of $71(69 \%)$ cases of PDA compared with seven of $18(39 \%)$ cases of chronic pancreatitis $(P=0.03) .{ }^{51}$ This research also revealed that median survival was nearly twice as long when EGFR was expressed (15.2 versus [vs] 8.3 months); however, this was not statistically significant. Other studies have shown that EGFR overexpression is either associated with decreased survival ${ }^{55,56}$ or not associated with survival at all. ${ }^{54}$

Research has also examined the role EGFR may play in the development of metastases from PDA. One IHC study demonstrated that EGF and EGFR expression correlated with lymph node involvement and metastases in 36 PDA patients. ${ }^{57}$ Another study revealed that EGFR overexpression was significantly associated with the metastatic status of the 77 cases examined. ${ }^{52}$ There is also evidence that EGFR may play a role in the $\mathrm{TME},{ }^{58}$ with inhibition of the pathway leading to apoptosis in endothelial cells in vivo. ${ }^{59}$ Therefore, although there is evidence of overexpression of EGFR in PDA and indications that it can play a role in metastatic development and the TME, the prognostic significance of these findings remains uncertain due to conflicting results in studies with mostly small numbers of patients.

\section{HER2}

HER2 amplification or overexpression is less commonly seen in pancreatic cancer compared with EGFR expression. When HER2 is overexpressed, it has been shown to correlate with shortened survival. ${ }^{60,61}$ A recent study using whole genome sequencing and single nucleotide polymorphism (SNP) arrays in a large cohort $(n=469)$ of PDA patients revealed HER 2 amplification in only $2 \%$ of PDA patients. ${ }^{62}$ Interestingly, in patients where HER 2 was amplified, there was a preponderance of lung and brain metastases, and a 
tendency to avoid liver metastases. ${ }^{62} \mathrm{~A}$ recent Phase II trial found HER2 overexpression present in $11 \%$ of patients. ${ }^{63}$ Due to low response rates, a post hoc analysis of patients' HER2 status was then performed. The investigators analyzed eleven out of 17 highly-overexpressing HER2 samples for HER 2 gene amplification. Interestingly, only seven samples tested positive (64\%) and there was no improvement in this trial in progression-free survival (PFS) or overall survival (OS) with anti-HER2 therapy (discussed in Targeting the EGFR pathway in PDA patients). Other studies, with fewer patient samples, have revealed HER2 expression (via IHC and gene amplification) in $16 \%-45 \%$ of patients with pancreatic cancer. ${ }^{61,64-66}$ In view of the discordance between HER2 amplification and IHC expression of HER2, there may be other active dysregulated cancer pathways contributing to the HER2 protein overexpression. The research performed to date suggests anti-HER2 therapy is unlikely to be effective unless combined with other molecularly targeted agents, with strong scientific rationale underlying the combination.

\section{HER3 and HER4}

Evidence for the function for HER3 and HER4 in the progression of pancreatic cancer has been underexamined compared with HER2 and EGFR. A recent meta-analysis investigated the role of HER3 overexpression and prognostic impact in solid tumors, revealing that overexpression of HER3 was associated with a worse survival in all of the studies analyzed, including one involving pancreatic cancer patients. ${ }^{67}$ The pancreatic cancer study in this meta-analysis examined tissue samples from 126 patients with pancreatic cancer and performed IHC for HER3. The researchers discovered HER3 overexpression in $41 \%$ of cases, which was associated with a poorer prognosis (HER3 overexpression median survival was 37.2 months, whereas HER3-negative sample median survival was 58.6 months $)(P=0.008)$. They did not examine other members of the EGFR family. Another study examined HER3 expression in normal human pancreas, human pancreatic cancer cell lines, and 58 human pancreatic carcinomas. ${ }^{68}$ This revealed an increase in HER3 messenger ribonucleic acid (mRNA) and protein levels in cancer compared with normal pancreas, which was associated with poorer survival and advanced tumor stage. However, a more recent report utilized tissue from 45 surgical patients with pancreatic cancer and examined all EGFR family members by IHC or in situ hybridization (ISH). ${ }^{69}$ The investigators discovered normal pancreatic tissues had HER3 and HER4 expression but no HER1 or HER2 expression. In the same patients, they then examined the pancreatic tumors and found loss of cytoplasmic HER3 and HER4 in 73\% and 18\% of cases, respectively. They did not find any of the HER family members to be associated with survival.

Other research has assessed HER4 expression and function in pancreatic tumor cell lines and tumors. ${ }^{70-72}$ HER4 transcription has been shown to be expressed in normal ductal cells but decreased in advanced disease, suggesting it may be a necessary for tumor initiation. ${ }^{71}$ HER4 is also thought to be associated with a favorable stage of tumor. ${ }^{72}$ The studies published to date suggest that HER4 may be important in the early stages of pancreatic cancer but not for the late stages.

In summary, as in the case of EGFR, the role of HER3 and HER4 in the progression of pancreatic cancer is controversial, with some studies revealing that overexpression is associated with a poor prognosis and some revealing no association. However, research has mainly been confined to retrospective studies in small cohorts of PDA patient tissue samples. Therapies to target HER3 and HER4 are in development; however, it is necessary to better understand their role in the progression of pancreatic cancer to decide whether this would be a potential therapeutic option for patients. Whether this could be performed in well-designed translational clinical trials or using cell lines and mouse models of pancreatic cancer remains to be determined.

\section{Targeted therapies, EGFR and pancreatic cancer Targeted therapies for PDA}

Since the majority of patients with PDA develop advanced metastatic disease, and chemotherapeutics have limited impact on survival, improvements in systemic-targeted therapies are desperately needed. As KRAS mutations are the commonest mutations found in PDA, this would be a logical therapeutic target. Unfortunately, the specific biochemical properties of the KRAS protein have made this a very difficult task to undertake and to date, there are no effective $K R A S$ inhibitors available. Apart from one randomized Phase III trial, the National Cancer Institute of Canada Clinical Trials Group (NCIC CTG) PA3 trial ${ }^{76}$ (discussed in Targeting the EGFR pathway in PDA patients), no targeted therapy studies have shown a significant improvement in median OS in advanced PDA, despite multiple different therapies being tested, alone and in combination. Recently, two trials investigating combined chemotherapy use in advanced PDA have reported encouraging results for improving OS. ${ }^{73-75}$ There 
is obviously potential for combining targeted agents with chemotherapy; however, the question of whether this will add any further benefit, without excessive toxicity, remains to be answered. Targeted agents can have toxicities, such as skin rash, hypertension, and gastrointestinal disturbances, which can all affect patients' quality of life, and for the small benefits seen thus far and high costs, there would be no reason to use these unless we develop potential biomarkers of response to treatment.

\section{Targeting the EGFR pathway in PDA patients}

Many different strategies have been utilized to target the EGFR pathway in pancreatic cancer patients. The two main approaches have examined the effects of TKIs and monoclonal antibodies. However, despite many encouraging Phase II trial results in advanced pancreatic cancer there has been an absence of clinically significant published results in the Phase II randomized or Phase III setting (Tables 1 and 2). Thus far, four phase III trials in advanced pancreatic cancer have been completed and published examining targeted therapies against EGFR (Table 1). Table 2 summarizes the majority of published Phase II trials involving anti-EGFRdirected therapies.

The NCIC CTG performed the only trial to demonstrate an OS benefit from the addition of EGFR-targeted therapy to standard gemcitabine chemotherapy in pancreatic cancer. ${ }^{76}$ This was a randomized, placebo-controlled, Phase III trial comparing erlotinib in combination with gemcitabine to gemcitabine alone, in patients with locally advanced or metastatic pancreatic cancer (the PA3 trial). The difference in median OS between the erlotinib and placebo groups was modest (6.24 months vs 5.91 months); however, there was a significant decrease in the hazard ratio (HR) for death $(0.82)$
$(P=0.04)$ and a significant improvement in the 1-year survival rate $(23 \%$ compared with $17 \%)(P=0.02) .{ }^{76}$ The outcome of patients treated with erlotinib was not related to EGFR status (assessed by IHC and fluorescence in situ hybridization [FISH]). ${ }^{76,77}$ Translational results from this trial are discussed in the section "EGFR and resistance in pancreatic cancer".

Following on from these results, a Phase III randomized study was initiated to investigate the addition of bevacizumab, a VEGF-inhibitor. Patients were randomized to receive placebo or bevacizumab, in combination with gemcitabine and erlotinib. The median OS was not significantly different between the two groups (6.0 months for the placebo arm compared with 7.1 months in the bevacizumab arm). ${ }^{78}$ Other Phase II trials have also examined the combination of EGFR(antibody or TKI-based treatment) and VEGF-targeted therapy in advanced pancreatic cancer, with no statistically significant differences in response rate or OS..$^{34,79,80} \mathrm{~A}$ further large VEGF study has also been negative, ${ }^{81}$ and the addition of VEGF therapy to EGFR therapy in advanced PDA should not be recommended unless biomarkers of VEGF response are discovered. ${ }^{82}$

The Phase III AIO-PK0104 trial randomized patients with advanced pancreatic cancer to either gemcitabine and erlotinib followed by capecitabine, or capecitabine and erlotinib followed by gemcitabine..$^{83}$ As both arms of the study contained erlotinib, they could not assess a difference in OS with the addition of an EGFR-targeted therapy. Interestingly, there were nearly identical survival statistics for the gemcitabine/erlotinib arm in AIO-PK0104 and in PA3. Both of these trials also found that skin rash strongly correlated with efficacy in pancreatic cancer patients treated with erlotinib. ${ }^{76,83}$ Based on the results of the PA3 trial, an interesting Phase II trial was undertaken to determine the efficacy of erlotinib, dosed to achieve a

Table I Summary of published randomized Phase III studies involving EGFR-targeted therapies for pancreatic cancer

\begin{tabular}{|c|c|c|c|c|c|c|c|}
\hline Reference & $\begin{array}{l}\text { EGFR study } \\
\text { treatment }\end{array}$ & Phase & $\begin{array}{l}\text { Treatment arms } \\
\text { of trial }\end{array}$ & $\begin{array}{l}\text { Patients } \\
\text { enrolled }\end{array}$ & $\begin{array}{l}\text { Primary } \\
\text { end point }\end{array}$ & $\begin{array}{l}\text { Median OS } \\
\text { (months) }\end{array}$ & $P$-value \\
\hline \multirow[t]{2}{*}{ Moore et al ${ }^{76}$} & Erlotinib & III & Gemcitabine & 284 & OS & 5.91 & 0.038 \\
\hline & & & Gemcitabine and erlotinib & 285 & & 6.24 & \\
\hline Van Cutsem & Erlotinib & III & Gemcitabine and erlotinib & 301 & OS & 6.0 & 0.2087 \\
\hline et $\mathrm{al}^{78}$ & & & $\begin{array}{l}\text { Gemcitabine, erlotinib, } \\
\text { and bevacizumab }\end{array}$ & 306 & & 7.1 & \\
\hline \multirow[t]{2}{*}{ Philip et $\mathrm{a}{ }^{87}$} & Cetuximab & III & Gemcitabine & 371 & OS & 5.9 & 0.23 \\
\hline & & & Gemcitabine and cetuximab & 372 & & 6.3 & \\
\hline \multirow[t]{2}{*}{$\begin{array}{l}\text { Heineman } \\
\text { et a }\left.\right|^{83}\end{array}$} & Erlotinib & III & $\begin{array}{l}\text { Gemcitabine and erlotinib } \\
\text { followed by capecitabine }\end{array}$ & 143 & $\begin{array}{l}\text { Noninferiority } \\
\text { comparison }\end{array}$ & 6.2 & 0.90 \\
\hline & & & $\begin{array}{l}\text { Capecitabine and erlotinib } \\
\text { followed by gemcitabine }\end{array}$ & $|3|$ & $\begin{array}{l}\text { (assessed by } \\
\text { TTF) }\end{array}$ & 6.9 & \\
\hline
\end{tabular}

Abbreviations: EGFR, epidermal growth factor receptor; OS, overall survival; TTF, time to treatment failure. 
Table 2 Summary of published Phase II studies involving EGFR-targeted therapies for pancreatic cancer

\begin{tabular}{|c|c|c|c|c|c|}
\hline Reference & Stage of disease & Study treatment & $\begin{array}{l}\text { Patients } \\
\text { enrolled }\end{array}$ & End points & $\begin{array}{l}\text { Median OS } \\
\text { (months) }\end{array}$ \\
\hline Herman et $\mathrm{al}^{97}$ & Resected (adjuvant) & Erlotinib, capecitabine, and IMRT & 48 & RFS & 24.4 \\
\hline López et al ${ }^{124}$ & Metastatic & Erlotinib and capecitabine & 32 & ORR & 4.3 \\
\hline Kordes et al ${ }^{117}$ & Locally advanced or metastatic & Everolimus, capecitabine, and cetuximab & 31 & ORR & 5.0 \\
\hline Hwang et al ${ }^{125}$ & Locally advanced or metastatic & Erlotinib, gemcitabine, and cisplatin & 22 & ORR & 6.8 \\
\hline Pipas et $\mathrm{al}^{94}$ & Operable (neoadjuvant) & Cetuximab, gemcitabine, and IMRT & 37 & Not stated & $\begin{array}{l}24.3 \text { (in } \\
\text { resected } \\
\text { patients) }\end{array}$ \\
\hline \multirow[t]{2}{*}{ Ko et $\mathrm{al}^{79}$} & Locally advanced or metastatic & Cetuximab and bevacizumab & 31 & PFS & 4.17 \\
\hline & & Cetuximab, bevacizumab, and gemcitabine & 30 & & 5.41 \\
\hline Oh et al ${ }^{126}$ & Metastatic & Erlotinib, gemcitabine, and capecitabine & 47 & PFS at 16 weeks & 12.0 \\
\hline Merchan et al ${ }^{127}$ & Locally advanced or metastatic & Cetuximab, gemcitabine, and oxaliplatin & 41 & PFS & 11.3 \\
\hline Strumberg et a ${ }^{93}$ & $\begin{array}{l}\text { Locally advanced or metastatic } \\
\text { second-line treatment }\end{array}$ & Nimotuzumab & 56 & RR, PFS & I8.I weeks \\
\hline Crane et $\mathrm{al}^{128}$ & Locally advanced & $\begin{array}{l}\text { Cetuximab, gemcitabine, oxaliplatin, } \\
\text { and radiation }\end{array}$ & 69 & OS (I year) & 19.2 \\
\hline Feliu et al ${ }^{129}$ & Locally advanced or metastatic & Erlotinib and gemcitabine-FDR & 42 & Efficacy and safety & 8.0 \\
\hline El-Rayes et al ${ }^{130}$ & Advanced or metastatic & Erlotinib, isoflavones, and gemcitabine & 20 & ORR, PFS, OS & 5.2 \\
\hline Bao et $a^{95}$ & Resected (adjuvant) & Erlotinib and gemcitabine & 25 & RFS & Not reached \\
\hline Ko et $\mathrm{al}^{80}$ & Metastatic second-line treatment & Erlotinib and bevacizumab & 36 & OS (at 6 months) & 102 days \\
\hline Kullmann et $\mathrm{al}^{131}$ & Metastatic & Cetuximab, gemcitabine, and oxaliplatin & 64 & $\mathrm{RR}$ & 213 days \\
\hline Brell et al99 & $\begin{array}{l}\text { Locally advanced or metastatic } \\
\text { second-line treatment }\end{array}$ & Gefitinib and docetaxel & 41 & Improved OS & 4.5 \\
\hline \multirow[t]{2}{*}{ Cascinu et a ${ }^{88}$} & Locally advanced or metastatic & Cetuximab, gemcitabine, and cisplatin & 42 & ORR & 7.5 \\
\hline & & Gemcitabine and cisplatin & 42 & & 7.8 \\
\hline Fountzilas et al ${ }^{132}$ & Locally advanced or metastatic & Gefitinib and gemcitabine & 53 & RR, PFS & 7.3 \\
\hline Ignatiadis et al ${ }^{133}$ & $\begin{array}{l}\text { Locally advanced or metastatic } \\
\text { second-line treatment }\end{array}$ & Gefitinib and docetaxel & 26 & ORR & 2.9 \\
\hline Xiong et $\mathrm{a}^{86}$ & Locally advanced or metastatic & $\begin{array}{l}\text { Cetuximab and gemcitabine (EGFR- } \\
\text { expressing tumors only) }\end{array}$ & 41 & $\begin{array}{l}\text { RR, TTP, } \\
\text { OS, safety }\end{array}$ & 7.1 \\
\hline
\end{tabular}

Abbreviations: EGFR, epidermal growth factor receptor; FDR, fixed dose rate; IMRT, intensity-modulated radiotherapy; ORR, objective response rate; OS, overall survival; PFS, progression-free survival; RFS, recurrence-free survival; RR, response rate; TTP, time to progression.

rash, in 50 patients with refractory advanced PDA. ${ }^{84}$ The dose of erlotinib was increased until $>$ grade 1 rash or other dose-limiting toxicities occurred. The primary end point was prolonged disease control (partial response plus stable disease for $>8$ weeks) and was observed in ten out of 40 evaluable patients. Another first-line study examined the effect of erlotinib dose escalation in patient with metastatic pancreatic cancer. ${ }^{85}$ In this study, the erlotinib dose-escalation strategy induced rash in $41 \%$ of patients but was not associated with increased clinical benefit compared with the standard erlotinib dose of $100 \mathrm{mg}$ /day.

The main monoclonal antibody against EGFR to have been tested in PDA is cetuximab, an IgG1 chimeric antibody. The combination of cetuximab and gemcitabine revealed promising results in a Phase II study; ${ }^{86}$ however, in the South-West Oncology Intergroup trial (SWOG-S0205), a randomized Phase III study in patients with advanced pancreatic cancer, the combination demonstrated no survival benefit compared with gemcitabine alone. ${ }^{87}$ In addition, EGFR overexpression was found in $92 \%$ of patients but did not predict a response to treatment. The addition of cetuximab to the chemotherapy agents gemcitabine and cisplatin also failed to improve OS in advanced pancreatic cancer patients. ${ }^{88}$ Panitumumab has also been investigated in a Phase II randomized trial comparing gemcitabine and erlotinib with either panitumumab or placebo. ${ }^{89}$ Interestingly, the median OS was significantly improved in the panitumumab-containing arm (8.4 months vs 4.0 months) $(P=0.077)$; however, there was a significantly higher rate of toxicity in this arm and concerningly low rates of survival in the standard arm. A Phase III trial of this combination has not been initiated.

There are far fewer clinical trials investigating agents against HER2, 3, and 4 in pancreatic cancer, probably due to the lack of expression of these targets and limited research thus far in the pancreatic cancer field. A few trials have evaluated trastuzumab in combination with gemcitabine, or other chemotherapeutics, in pancreatic cancer. Unfortunately, there have been minimal effects on either PFS or OS to date. ${ }^{63,66}$ Pertuzumab is an inhibitor 
of HER dimerization that blocks ligand-dependent heterodimerization of HER2 with other family members. A Phase II trial of pertuzumab and erlotinib in advanced pancreatic cancer patients was terminated early due to excessive toxicity. ${ }^{90}$ Another Phase II trial with lapatinib, a small-molecule pan-HER inhibitor, in combination with gemcitabine, was terminated early due to futility at the interim analysis as the patients in the lapatinib arm had progressed early, with a median OS of 4 months. ${ }^{91}$ There have been some encouraging Phase II results with a monoclonal antibody, nimotuzumab, which binds with high affinity to the HER receptors..$^{92,93}$ A Phase III trial of nimotuzumab in combination with gemcitabine is still underway. Specific anti-HER3 and -HER4 agents, to our knowledge, are yet to be tested in pancreatic cancer.

Anti-EGFR therapies have also been used in combination with chemotherapy and radiotherapy in the neoadjuvant and adjuvant setting. ${ }^{94-97}$ The largest Phase III study using chemoradiotherapy and EGFR-based therapy, the LAP07 study, was presented at the American Society of Clinical Oncology (ASCO) Annual Meeting in 2013. ${ }^{98}$ In this study, 442 patients with locally advanced pancreatic cancer were randomized to gemcitabine alone or gemcitabine and erlotinib. Patients with controlled disease $(n=269)$ were then randomized to 2 additional months of chemotherapy or chemoradiotherapy (using capecitabine). If patients received erlotinib initially, they then received maintenance erlotinib after protocol completion. A planned interim analysis revealed chemoradiotherapy was not superior to continuing chemotherapy in patients with controlled locally advanced pancreatic cancer. The median OS of gemcitabine and erlotinib was only 11.9 months compared with 13.6 months in the gemcitabine-alone arm $(P=0.09)$, with no difference in PFS. There was also increased toxicity in the erlotinib-containing arm. Therefore erlotinib would not be recommended in patients with locally advanced pancreatic cancer.

EGFR therapies have also been used in refractory advanced PDA, with little success. ${ }^{80,99}$ The majority of these studies suffer from small patient numbers, lack of associated translational substudies, and increasing toxicities with increasing number of therapies utilized. In view of all the positive Phase II trial results and subsequently negative Phase III trials in PDA it remains to be determined whether EGFR-directed antibody therapy could be useful in the setting of advanced PDA without a predictive biomarker. It is also difficult to know whether the doses of anti-EGFR agents used are expected to achieve the same level of dose inhibition of the EGFR pathway. In fact, there is very little evidence of the effect the EGFR therapies are actually having on PDA tumors and the pathways that may be down- or upregulated as a consequence of this.

To date, there have been no Phase III studies in pancreatic cancer using selective biomarkers to predict patient response, and few translational substudies from the Phase II and III trials. However efforts are underway to try and identify biomarkers predictive of response to anti-EGFR therapies. A recent presentation revealed that amphiregulin may be of relevance as patients with elevated baseline levels of amphiregulin obtained benefits in both PFS and OS with erlotinib. ${ }^{100}$ Although genotype and molecular assessment may be useful in determining which patients are most likely to respond to treatment, the nature of pancreatic cancer makes it particularly challenging to obtain adequate samples for such analyses.

\section{EGFR and resistance in pancreatic cancer KRAS mutations}

It would be reasonable to suspect the high frequency of $K R A S$ mutations in PDA could affect the efficacy of EGFR inhibitors, such as the effect seen in colorectal cancers. ${ }^{101}$ With a mutated KRAS gene, the KRAS protein remains switched "on", and signaling within the tumor cells continues despite EGFR blockade. The correlation between KRAS status and OS was investigated in the NCIC CTG PA.3 trial. ${ }^{77} \mathrm{KRAS}$ mutations were examined in 117 patients on the trial and were present in $79 \%$ of cases. The HR for erlotinib in this group was 1.07 , whereas in patients with wild-type $K R A S(21 \%)$, the HR was 0.66. This difference did not reach statistical significance, likely because of the small number of patients with wild-type $K R A S{ }^{77}$ The sequencing method may also have affected sensitivity, therefore deeper sequencing of the samples from this study is currently underway using nextgeneration sequencing.

Two recent translational research papers have been published from the Phase III AIO-PK0104 trial, in which both treatment arms contained erlotinib. ${ }^{54,83}$ One paper examined the role of EGFR pathway biomarkers in archival tissue collected from the patients. KRAS mutations were found in $70 \%$, and EGFR overexpression (via IHC) was found in $49 \%$ of patients. The researchers also found (via FISH) that $46 \%$ of patients had EGFR gene amplification, and $18 \%$ had loss of PTEN. There was no correlation between EGFR overexpression and $E G F R$ gene amplification. None of these biomarkers could be correlated with efficacy end points. ${ }^{54}$ 
The second paper examined the correlation between $K R A S$ mutational status and objective response rates, and found that $K R A S$ mutations were not predictive for objective response to anti-EGFR treatment in patients with advanced pancreatic cancer. ${ }^{102}$ However, KRAS wild-type status was associated with an improved OS regardless of treatment, which has also been presented in a recent retrospective analysis of cases. ${ }^{103}$ In this latter study, patients who received gemcitabine/ erlotinib and had a KRAS mutation had a median survival of 5.2 months, whereas the median survival for patients with wild-type $K R A S$ was 9.7 months. Interestingly, KRAS mutation status was not associated with clinical outcomes in patients who underwent chemotherapy with regimens other than gemcitabine/erlotinib (KRAS mutation, 7.0 months vs wild-type KRAS, 7.0 months $)(P=0.21) .{ }^{103}$

In summary, studies thus far have shown $K R A S$ status is likely to be a prognostic rather than a predictive biomarker in pancreatic cancer. ${ }^{77,102}$ It would be very helpful to have further information on $K R A S$ and EGFR status from other randomized studies, such as the SWOG intergroup S0205 trial of cetuximab and gemcitabine vs gemcitabine alone. ${ }^{87}$ This would provide us with further information on the role $K R A S$ plays in relation to EGFR-based therapies, in a large cohort of patient samples.

\section{Mutations in EGFR}

In non-small-cell lung cancer (NSCLC), tumors with activating mutations in $E G F R$ have shown better survival and response to EGFR TKIs. ${ }^{104}$ However, in PDA, activating mutations have rarely been reported using basic sequencing technologies. ${ }^{105,106}$ EGFR in-frame deletions were only found in 4\% (two out of 55) of patients with PDA, in one study, ${ }^{105}$ and no mutations ( 0 out of 43 ) in EGFR exons 18-21 were found in another study. ${ }^{106}$ A further study analyzed EGFR mutations in nine pancreatic cancer cell lines and 31 resected human pancreatic cancer specimens. ${ }^{107}$ This study utilized laser capture microdissection (LCM) to ensure the tumor cells were analyzed and identified silent mutations in $81 \%$ of cases, concluding that EGFR mutation status seems to be a less helpful predictive biomarker in pancreatic cancer than in NSCLC. ${ }^{107}$

\section{Nuclear expression of EGFR}

Nuclear EGFR has also been implicated in the resistance to various cancer therapies, including cetuximab and gefitinib. Cell lines resistant to these therapies often express high levels of nuclear EGFR. ${ }^{108,109}$ Preclinically, nuclear localization of
EGFR has been shown to play a role, in resistance to radiotherapy and chemotherapy. Recent comprehensive reviews examining the role nuclear EGFR plays in cancer and resistance can be found elsewhere. ${ }^{29,110}$ The nuclear expression of EGFR and the role it could play in resistance to therapies in PDA is yet to be determined. There has been one recent study that examined nuclear and cytoplasmic EGFR expression via IHC in 99 PDA patients. Although the researchers did not report any nuclear EGFR expression in the samples examined, ${ }^{9}$ it is important to note that nuclear EGFR is not accurately targeted by anti-EGFR kinase inhibitors and that nuclear EGFR function may be independent of its kinase activity. ${ }^{111,112}$

\section{EGFR and other signaling pathways}

Cross talk of EGFR signaling with other signaling pathways can also give rise to potential resistance mechanisms. Similarly, downstream components of the EGFR pathway may play a more significant role in identifying drug-sensitive patients than just cell surface expression. It has been shown preclinically that the PI3K/Akt pathway plays a number of roles in resistance to EGFR inhibitors. EGFR TKI-resistant cell lines of squamous cell cancer maintain activation of the PI3K pathway due to increased activity of the insulin-like growth factor 1 receptor (IGF1R) pathway. The addition of an IGF1R pathway inhibitor to an EGFR inhibitor was found to lead to inhibit of PI3K activity in cell lines and significantly improve responses in xenograft squamous cell carcinoma mouse models. ${ }^{113}$ Cross talk between the two pathways has also been examined in pancreatic cancer. ${ }^{114}$ However, when this combined approach was translated into a Phase II clinical trial, using cixutumumab (a novel inhibitor of IGF1R), erlotinib, and gemcitabine in pancreatic cancer patients, there was no improvement in PFS or OS. ${ }^{115}$

The mammalian target of rapamycin (mTOR), a downstream mediator of the PI3K-Akt pathway, has also been examined in resistance mechanisms to EGFR therapies. In combination with cetuximab or gefitinib, the addition of the mTOR-inhibitor everolimus resulted in a strong reduction of PI3K/Akt activity. ${ }^{116}$ However, a Phase I/II study to explore the safety and efficacy of pathway inhibition utilizing cetuximab and everolimus in combination with capecitabine in patients with advanced pancreatic cancer resulted in excess toxicity and low efficacy. ${ }^{117}$

Amplification of MET can also lead to EGFR-independent activation of PI3K-Akt, through the activation of HER3dependent signaling. ${ }^{118}$ Examination of tumor samples from lung cancer patients who developed resistance to EGFR TKI 
therapy revealed MET gene amplification that was not present in tumor samples prior to treatment. ${ }^{118} \mathrm{MET}$ is known to be amplified in up to $50 \%$ of pancreatic cancer patients; however, there has been limited research to understand the interplay between EGFR and MET amplification in this setting. ${ }^{119}$ Early-stage clinical trials using MET-inhibitors are currently underway.

Various mechanisms of resistance to anti-EGFR-directed therapies and until recently, lack of predictive biomarkers have limited the use of these drugs as single agents. ${ }^{12,120}$ Recently, there has also been interest in developing therapies that inhibit more than one component of the EGFR receptor family. ${ }^{18,121}$ This has arisen because preclinical research has suggested that using two inhibitors against individual EGFR family members, particularly EGFR and HER2, can lead to distinctly higher antitumor activity than the administration of single agents. ${ }^{18}$ An excellent comprehensive overview of current resistance mechanisms to EGFR-based therapies, and potential ways to overcome these has recently been published. ${ }^{122}$

\section{The future}

Pancreatic cancer has proven highly resistant to EGFRtargeted therapies through several postulated mechanisms with EGFR mutational status, gene copy number and EGFR overexpression, as well as crosstalk with other signal transduction pathways implicated in regulating response to treatment. Furthermore, pancreatic tumors are frequently hypovascular and may therefore limit drug delivery. ${ }^{123}$ Several recent attempts to overcome resistance mechanisms have provided encouraging results in preclinical models, however their application in clinical trials remains untested. The high attrition rate between Phase II and Phase III clinical trials underscores the requirement for more robust methods of clinically assessing the EGFR pathway. The future lies in well-designed trials that incorporate multiple biological endpoints to assess the novel targets under investigation. It is likely that, rather than providing incremental benefits in all patients, EGFR-targeted therapies will provide significant benefits to a small subset of patients. Without biomarkers to distinguish these subsets we cannot currently recommend the further use of EGFRtargeted therapies for the treatment of pancreatic cancer. However, our increased understanding of EGFR inhibitors and potential biomarkers of their activity, alongside our improved knowledge of the biology of pancreatic cancer, may make targeting EGFR a viable therapeutic option in the future.

\section{Disclosure}

The authors report no conflicts of interest in this work.

\section{References}

1. Siegel R, Naishadham D, Jemal A. Cancer statistics, 2013. CA Cancer J Clin. 2013;63(1):11-30.

2. Casalini P, Iorio MV, Galmozzi E, Ménard S. Role of HER receptors family in development and differentiation. J Cell Physiol. 2004;200(3): $343-350$.

3. Alexandrov LB, Nik-Zainal S, Wedge DC, et al; Australian Pancreatic Cancer Genome Initiative; ICGC Breast Cancer Consortium; ICGC MMML-Seq Consortium; ICGC PedBrain. Signatures of mutational processes in human cancer. Nature. 2013;500(7463): 415-421.

4. Siveke JT, Crawford HC. KRAS above and beyond-EGFR in pancreatic cancer. Oncotarget. 2012;3(11):1262-1263.

5. Yarden Y, Pines G. The ERBB network: at last, cancer therapy meets systems biology. Nat Rev Cancer. 2012;12(8):553-563.

6. Dongbin L, Fei L, Werner Josefin B, Roland A. Intraductal papillary mucinous neoplasms of the pancreas: diagnosis and management. Eur J Gastroenterol Hepatol. 2010;22(9):1029-1038.

7. Hruban RH, Maitra A, Goggins M. Update on pancreatic intraepithelial neoplasia. Int J Clin Exp Pathol. 2008;1(4):306-316.

8. Hingorani SR, Petricoin EF, Maitra A, et al. Preinvasive and invasive ductal pancreatic cancer and its early detection in the mouse. Cancer Cell. 2003;4(6):437-450.

9. Handra-Luca A, Hammel P, Sauvanet A, Lesty C, Ruszniewski P, Couvelard A. EGFR expression in pancreatic adenocarcinoma. Relationship to tumour morphology and cell adhesion proteins. J Clin Pathol. Epub October 29, 2013.

10. Hezel AF, Kimmelman AC, Stanger BZ, Bardeesy N, Depinho RA. Genetics and biology of pancreatic ductal adenocarcinoma. Genes Dev. 2006;20(10):1218-1249.

11. Smit VT, Boot AJ, Smits AM, Fleuren GJ, Cornelisse CJ, Bos JL. KRAS codon 12 mutations occur very frequently in pancreatic adenocarcinomas. Nucleic Acids Res. 1988;16(16):7773-7782.

12. Scheffzek K, Ahmadian MR, Kabsch W, et al. The Ras-RasGAP complex: structural basis for GTPase activation and its loss in oncogenic Ras mutants. Science. 1997;277(5324):333-338.

13. Bardeesy N, Aguirre AJ, Chu GC, et al. Both p16(Ink4a) and the p19(Arf)p53 pathway constrain progression of pancreatic adenocarcinoma in the mouse. Proc Natl Acad Sci U S A. 2006;103(15):5947-5952.

14. Redston MS, Caldas C, Seymour AB, et al. p53 mutations in pancreatic carcinoma and evidence of common involvement of homocopolymer tracts in DNA microdeletions. Cancer Res. 1994;54(11): 3025-3033.

15. Hansel DE, Kern SE, Hruban RH. Molecular pathogenesis of pancreatic cancer. Annu Rev Genomics Hum Genet. 2003;4:237-256.

16. Maitra A, Adsay NV, Argani P, et al. Multicomponent analysis of the pancreatic adenocarcinoma progression model using a pancreatic intraepithelial neoplasia tissue microarray. Mod Pathol. 2003;16(9):902-912.

17. Yarden Y, Sliwkowski MX. Untangling the ErbB signalling network. Nat Rev Mol Cell Biol. 2001;2(2):127-137.

18. Tebbutt N, Pedersen MW, Johns TG. Targeting the ERBB family in cancer: couples therapy. Nat Rev Cancer. 2013;13(9):663-673.

19. Seshacharyulu P, Ponnusamy MP, Haridas D, Jain M, Ganti AK, Batra SK. Targeting the EGFR signaling pathway in cancer therapy. Expert Opin Ther Targets. 2012;16(1):15-31.

20. Brennan PJ, Kumagai T, Berezov A, Murali R, Greene MI, Kumogai T. HER2/neu: mechanisms of dimerization/oligomerization. Oncogene. 2000;19(53):6093-6101.

21. Lin SY, Makino K, Xia W, et al. Nuclear localization of EGF receptor and its potential new role as a transcription factor. Nat Cell Biol. 2001;3(9):802-808. 
22. Lo HW, Hsu SC, Ali-Seyed M, et al. Nuclear interaction of EGFR and STAT3 in the activation of the iNOS/NO pathway. Cancer Cell. 2005;7(6):575-589.

23. Lo HW, Ali-Seyed M, Wu Y, Bartholomeusz G, Hsu SC, Hung MC. Nuclear-cytoplasmic transport of EGFR involves receptor endocytosis, importin beta1 and CRM1. J Cell Biochem. 2006;98(6): $1570-1583$.

24. Hynes NE, Lane HA. ERBB receptors and cancer: the complexity of targeted inhibitors. Nat Rev Cancer. 2005;5(5):341-354.

25. Xia W, Wei Y, Du Y, et al. Nuclear expression of epidermal growth factor receptor is a novel prognostic value in patients with ovarian cancer. Mol Carcinog. 2009;48(7):610-617.

26. Psyrri A, Yu Z, Weinberger PM, et al. Quantitative determination of nuclear and cytoplasmic epidermal growth factor receptor expression in oropharyngeal squamous cell cancer by using automated quantitative analysis. Clin Cancer Res. 2005;11(16):5856-5862.

27. Lo HW, Hsu SC, Hung MC. EGFR signaling pathway in breast cancers: from traditional signal transduction to direct nuclear translocalization. Breast Cancer Res Treat. 2006;95(3):211-218.

28. Traynor AM, Weigel TL, Oettel KR, et al. Nuclear EGFR protein expression predicts poor survival in early stage non-small cell lung cancer. Lung Cancer. 2013;81(1):138-141.

29. Brand TM, Iida M, Li C, Wheeler DL. The nuclear epidermal growth factor receptor signaling network and its role in cancer. Discov Med. 2011;12(66):419-432.

30. Lo HW, Cao X, Zhu H, Ali-Osman F. Cyclooxygenase-2 is a novel transcriptional target of the nuclear EGFR-STAT3 and EGFRvIII-STAT3 signaling axes. Mol Cancer Res. 2010;8(2):232-245.

31. Jaganathan S, Yue P, Paladino DC, Bogdanovic J, Huo Q, Turkson J. A functional nuclear epidermal growth factor receptor, SRC and Stat3 heteromeric complex in pancreatic cancer cells. PLoS One. 2011;6(5):e19605.

32. Ferrara N, Kerbel RS. Angiogenesis as a therapeutic target. Nature. 2005;438(7070):967-974.

33. De Luca A, Carotenuto A, Rachiglio A, et al. The role of the EGFR signaling in tumor microenvironment. $J$ Cell Physiol. 2008;214(3): 559-567.

34. Faller BA, Burtness B. Treatment of pancreatic cancer with epidermal growth factor receptor-targeted therapy. Biologics. 2009;3:419-428.

35. Cobleigh MA, Vogel CL, Tripathy D, et al. Multinational study of the efficacy and safety of humanized anti-HER2 monoclonal antibody in women who have HER2-overexpressing metastatic breast cancer that has progressed after chemotherapy for metastatic disease. J Clin Oncol. 1999;17(9):2639-2648.

36. Ramalingam SS, Blackhall F, Krzakowski M, et al. Randomized phase II study of dacomitinib (PF-00299804), an irreversible panhuman epidermal growth factor receptor inhibitor, versus erlotinib in patients with advanced non-small-cell lung cancer. J Clin Oncol. 2012;30(27):3337-3344.

37. Day JD, Digiuseppe JA, Yeo C, et al. Immunohistochemical evaluation of HER-2/neu expression in pancreatic adenocarcinoma and pancreatic intraepithelial neoplasms. Hum Pathol. 1996;27(2): $119-124$.

38. Zhu L, Shi G, Schmidt CM, Hruban RH, Konieczny SF. Acinar cells contribute to the molecular heterogeneity of pancreatic intraepithelial neoplasia. Am J Pathol. 2007;171(1):263-273.

39. Jhappan C, Stahle C, Harkins RN, Fausto N, Smith GH, Merlino GT. TGF alpha overexpression in transgenic mice induces liver neoplasia and abnormal development of the mammary gland and pancreas. Cell. 1990;61(6):1137-1146.

40. Sandgren EP, Luetteke NC, Palmiter RD, Brinster RL, Lee DC. Overexpression of TGF alpha in transgenic mice: induction of epithelial hyperplasia, pancreatic metaplasia, and carcinoma of the breast. Cell. 1990;61(6):1121-1135.

41. Wagner M, Greten FR, Weber CK, et al. A murine tumor progression model for pancreatic cancer recapitulating the genetic alterations of the human disease. Genes Dev. 2001;15(3):286-293.
42. Visser CJ, Bruggink AH, Korc M, et al. Overexpression of transforming growth factor-alpha and epidermal growth factor receptor, but not epidermal growth factor, in exocrine pancreatic tumours in hamsters. Carcinogenesis. 1996;17(4):779-785.

43. Means AL, Meszoely IM, Suzuki K, et al. Pancreatic epithelial plasticity mediated by acinar cell transdifferentiation and generation of nestinpositive intermediates. Development. 2005;132(16):3767-3776.

44. Sawey ET, Johnson JA, Crawford HC. Matrix metalloproteinase 7 controls pancreatic acinar cell transdifferentiation by activating the Notch signaling pathway. Proc Natl Acad Sci U S A. 2007;104(49): 19327-19332.

45. Ardito CM, Grüner BM, Takeuchi KK, et al. EGF receptor is required for KRAS-induced pancreatic tumorigenesis. Cancer Cell. 2012;22(3):304-317.

46. Navas C, Hernández-Porras I, Schuhmacher AJ, Sibilia M, Guerra C, Barbacid M. EGF receptor signaling is essential for k-ras oncogene-driven pancreatic ductal adenocarcinoma. Cancer Cell. 2012;22(3): 318-330.

47. Garnett MJ, Edelman EJ, Heidorn SJ, et al. Systematic identification of genomic markers of drug sensitivity in cancer cells. Nature. 2012; 483(7391):570-575.

48. De Roock W, Claes B, Bernasconi D et at. Effects of KRAS, BRAF, NRAS, and PIK3CA mutations on the efficacy of cetuximab plus chemotherapy in chermoterapy-refractory metastatic colorectal cancer: a retrospective consortium analysis. Lancet Oncol. 2010;11(8):753-62.

49. Jimeno A, Tan AC, Coffa J, et al. Coordinated epidermal growth factor receptor pathway gene overexpression predicts epidermal growth factor receptor inhibitor sensitivity in pancreatic cancer. Cancer Res. 2008;68(8):2841-2849.

50. Uegaki K, Nio Y, Inoue Y, et al. Clinicopathological significance of epidermal growth factor and its receptor in human pancreatic cancer. Anticancer Res. 1997;17(5B):3841-3847.

51. Bloomston M, Bhardwaj A, Ellison EC, Frankel WL. Epidermal growth factor receptor expression in pancreatic carcinoma using tissue microarray technique. Dig Surg. 2006;23(1-2):74-79.

52. Tobita K, Kijima H, Dowaki S, et al. Epidermal growth factor receptor expression in human pancreatic cancer: Significance for liver metastasis. Int J Mol Med. 2003;11(3):305-309.

53. Yamanaka Y, Friess H, Kobrin MS, Buchler M, Beger HG, Korc M. Coexpression of epidermal growth factor receptor and ligands in human pancreatic cancer is associated with enhanced tumor aggressiveness. Anticancer Res. 1993;13(3):565-569.

54. Boeck S, Jung A, Laubender RP, et al. EGFR pathway biomarkers in erlotinib-treated patients with advanced pancreatic cancer: translational results from the randomised, crossover phase 3 trial AIO-PK0104. Br J Cancer. 2013;108(2):469-476.

55. Perini MV, Montagnini AL, Coudry R, et al. Prognostic significance of epidermal growth factor receptor overexpression in pancreas cancer and nodal metastasis. ANZ J Surg. Epub September 25, 2013.

56. Einama T, Ueda S, Tsuda H, et al. Membranous and cytoplasmic expression of epidermal growth factor receptor in metastatic pancreatic ductal adenocarcinoma. Exp Ther Med. 2012;3(6):931-936.

57. Pryczynicz A, Guzińska-Ustymowicz K, Kemona A, Czyzewska J. Expression of EGF and EGFR strongly correlates with metastasis of pancreatic ductal carcinoma. Anticancer Res. 2008;28(2B):1399-1404.

58. Yamanaka Y. The immunohistochemical expressions of epidermal growth factors, epidermal growth factor receptors and c-erbB-2 oncoprotein in human pancreatic cancer. Nihon Ika Daigaku Zasshi. 1992;59(1):51-61.

59. Bruns CJ, Solorzano CC, Harbison MT, et al. Blockade of the epidermal growth factor receptor signaling by a novel tyrosine kinase inhibitor leads to apoptosis of endothelial cells and therapy of human pancreatic carcinoma. Cancer Res. 2000;60(11):2926-2935.

60. Lei S, Appert HE, Nakata B, Domenico DR, Kim K, Howard JM. Overexpression of HER $2 /$ neu oncogene in pancreatic cancer correlates with shortened survival. Int J Pancreatol. 1995;17(1):15-21.

61. Komoto M, Nakata B, Amano R, et al. HER2 overexpression correlates with survival after curative resection of pancreatic cancer. Cancer Sci. 2009;100(7):1243-1247. 
62. Chou A, Waddell N, Cowley MJ, et al. Clinical and molecular characterization of HER2 amplified-pancreatic cancer. Genome Med. 2013;5(8):78.

63. Harder J, Ihorst G, Heinemann V, et al. Multicentre phase II trial of trastuzumab and capecitabine in patients with HER2 overexpressing metastatic pancreatic cancer. Br J Cancer. 2012;106(6):1033-1038.

64. Yamanaka Y, Friess H, Kobrin MS, et al. Overexpression of HER2/ neu oncogene in human pancreatic carcinoma. Hum Pathol. 1993;24(10):1127-1134.

65. Safran H, Steinhoff M, Mangray S, et al. Overexpression of the HER-2/neu oncogene in pancreatic adenocarcinoma. Am J Clin Oncol. 2001;24(5):496-499

66. Safran H, Iannitti D, Ramanathan R, et al. Herceptin and gemcitabine for metastatic pancreatic cancers that overexpress HER-2/neu. Cancer Invest. 2004;22(5):706-712.

67. Ocana A, Vera-Badillo F, Seruga B, Templeton A, Pandiella A, Amir E. HER3 overexpression and survival in solid tumors: a metaanalysis. J Natl Cancer Inst. 2013;105(4):266-273.

68. Friess H, Yamanaka Y, Kobrin MS, Do DA, Büchler MW, Korc M. Enhanced erbB-3 expression in human pancreatic cancer correlates with tumor progression. Clin Cancer Res. 1995;1(11):1413-1420.

69. te Velde EA, Franke AC, van Hillegersberg R, et al. HER-family gene amplification and expression in resected pancreatic cancer. Eur J Surg Oncol. 2009;35(10):1098-1104.

70. Mill CP, Gettinger KL, Riese DJ. Ligand stimulation of ErbB4 and a constitutively-active ErbB4 mutant result in different biological responses in human pancreatic tumor cell lines. Exp Cell Res. 2011;317(4):392-404.

71. Graber HU, Friess H, Kaufmann B, et al. ErbB-4 mRNA expression is decreased in non-metastatic pancreatic cancer. Int $J$ Cancer. 1999;84(1):24-27.

72. Thybusch-Bernhardt A, Beckmann S, Juhl H. Comparative analysis of the EGF-receptor family in pancreatic cancer: expression of HER-4 correlates with a favourable tumor stage. Int J Surg Investig. 2001;2(5):393-400.

73. Conroy T, Desseigne F, Ychou M, et al; Groupe Tumeurs Digestives of Unicancer; PRODIGE Intergroup. FOLFIRINOX versus gemcitabine for metastatic pancreatic cancer. N Engl J Med. 2011;364(19): 1817-1825.

74. Von Hoff DD, Ervin T, Arena FP, et al. Increased survival in pancreatic cancer with nab-paclitaxel plus gemcitabine. $N$ Engl J Med. 2013;369(18):1691-1703.

75. Vaccaro V, Sperduti I, Milella M. FOLFIRINOX versus gemcitabine for metastatic pancreatic cancer. $N$ Engl J Med. 2011;365(8):768-769; author reply 769

76. Moore MJ, Goldstein D, Hamm J, et al; National Cancer Institute of Canada Clinical Trials Group. Erlotinib plus gemcitabine compared with gemcitabine alone in patients with advanced pancreatic cancer: a phase III trial of the National Cancer Institute of Canada Clinical Trials Group. J Clin Oncol. 2007;25(15):1960-1966.

77. da Cunha Santos G, Dhani N, Tu D, et al. Molecular predictors of outcome in a phase 3 study of gemcitabine and erlotinib therapy in patients with advanced pancreatic cancer: National Cancer Institute of Canada Clinical Trials Group Study PA.3. Cancer. 2010;116(24):5599-5607.

78. Van Cutsem E, Vervenne WL, Bennouna J, et al. Phase III trial of bevacizumab in combination with gemcitabine and erlotinib in patients with metastatic pancreatic cancer. J Clin Oncol. 2009;27(13):2231-2237.

79. Ko AH, Youssoufian H, Gurtler J, et al. A phase II randomized study of cetuximab and bevacizumab alone or in combination with gemcitabine as first-line therapy for metastatic pancreatic adenocarcinoma. Invest New Drugs. 2012;30(4):1597-1606.

80. Ko AH, Venook AP, Bergsland EK, et al. A phase II study of bevacizumab plus erlotinib for gemcitabine-refractory metastatic pancreatic cancer. Cancer Chemother Pharmacol. 2010;66(6):1051-1057.

81. Kindler HL, Ioka T, Richel DJ, et al. Axitinib plus gemcitabine versus placebo plus gemcitabine in patients with advanced pancreatic adenocarcinoma: a double-blind randomised phase 3 study. Lancet Oncol. 2011;12(3):256-262.
82. Tian W, Ding W, Kim S, Xu X, Pan M, Chen S. Efficacy and safety profile of combining agents against epidermal growth factor receptor or vascular endothelium growth factor receptor with gemcitabine-based chemotherapy in patients with advanced pancreatic cancer: a metaanalysis. Pancreatology. 2013;13(4):415-422.

83. Heinemann V, Vehling-Kaiser U, Waldschmidt D, et al. Gemcitabine plus erlotinib followed by capecitabine versus capecitabine plus erlotinib followed by gemcitabine in advanced pancreatic cancer: final results of a randomised phase 3 trial of the 'Arbeitsgemeinschaft Internistische Onkologie’ (AIO-PK0104). Gut. 2013;62(5): 751-759.

84. Tang PG, Gill S, Au HJ, et al. Phase II trial of erlotinib in advanced pancreatic cancer (PC) [abstract]. J Clin Oncol. 2009;27(15S):4609.

85. van Cutsem E, Nowara E, Ciuleanu T, et al. Dose escalation to rash for erlotinib plus gemcitabine in patients with metastatic pancreatic cancer: The phase II RACHEL (BO21128) study. Ann Oncol. 2012;23(4): iv5-iv18.

86. Xiong HQ, Rosenberg A, LoBuglio A, et al. Cetuximab, a monoclonal antibody targeting the epidermal growth factor receptor, in combination with gemcitabine for advanced pancreatic cancer: a multicenter phase II Trial. J Clin Oncol. 2004;22(13):2610-2616.

87. Philip PA, Benedetti J, Corless CL, et al. Phase III study comparing gemcitabine plus cetuximab versus gemcitabine in patients with advanced pancreatic adenocarcinoma: Southwest Oncology Group-directed intergroup trial S0205. J Clin Oncol. 2010;28(22):3605-3610.

88. Cascinu S, Berardi R, Labianca R, et al; Italian Group for the Study of Digestive Tract Cancer (GISCAD). Cetuximab plus gemcitabine and cisplatin compared with gemcitabine and cisplatin alone in patients with advanced pancreatic cancer: a randomised, multicentre, phase II trial. Lancet Oncol. 2008;9(1):39-44.

89. Kim GP, Foster NR, Salim M, et al. Randomised phase II trial of panitumumab $(\mathrm{P})$, erlotinib $(\mathrm{E})$, and gemcitabine $(\mathrm{G})$ versus erlotinibgemcitabine in patients with untreated, metastatic pancreatic adenocarcinoma [abstract]. J Clin Oncol. 2011;29(4):238.

90. Genentech. Phase II study of pertuzumab and erlotinib for refractory pancreatic adenocarcinoma. Available from: http://clinicaltrials.gov/ct2/ show/NCT01108458?term=NCT01108458\&rank=1. NLM identifier: NCT01108458. Accessed January 9, 2014.

91. Safran HM, Minor T, Bahary N, et al. Lapatinib and gemcitabine for metastatic pancreatic cancer: a phase II study. Am J Clin Oncol. 2009;27:e15653.

92. Strumberg D, Schultheis B, Scheulen ME, et al. Safety, efficacy and pharmacokinetics of nimotuzumab, a humanized monoclonal antiepidermal growth factor receptor (EGFR) antibody, in patients with locally advanced or metastatic pancreatic cancer. Int J Clin Pharmacol Ther. 2010;48(7):473-475.

93. Strumberg D, Schultheis B, Scheulen ME, et al. Phase II study of nimotuzumab, a humanized monoclonal anti-epidermal growth factor receptor (EGFR) antibody, in patients with locally advanced or metastatic pancreatic cancer. Invest New Drugs. 2012;30(3): 1138-1143.

94. Pipas JM, Zaki BI, McGowan MM, et al. Neoadjuvant cetuximab, twice-weekly gemcitabine, and intensity-modulated radiotherapy (IMRT) in patients with pancreatic adenocarcinoma. Ann Oncol. 2012;23(11):2820-2827.

95. Bao PQ, Ramanathan RK, Krasinkas A, et al. Phase II study of gemcitabine and erlotinib as adjuvant therapy for patients with resected pancreatic cancer. Ann Surg Oncol. 2011;18(4):1122-1129.

96. Arnoletti JP, Frolov A, Eloubeidi M, et al. A phase I study evaluating the role of the anti-epidermal growth factor receptor (EGFR) antibody cetuximab as a radiosensitizer with chemoradiation for locally advanced pancreatic cancer. Cancer Chemother Pharmacol. 2011;67(4):891-897.

97. Herman JM, Fan KY, Wild AT, et al. Phase 2 study of erlotinib combined with adjuvant chemoradiation and chemotherapy in patients with resectable pancreatic cancer. Int J Radiat Oncol Biol Phys. 2013;86(4):678-685. 
98. Hammel P, Huquet F, van Laethem JL, et al. Comparison of chemoradiotherapy (CRT) and chemotherapy (CT) in patients with a locally advanced pancreatic cancer (LAPC) controlled after 4 months of gemcitabine with or without erlotinib: Final results of the international phase III LAP 07 study. Paper presented at: 2013 ASCO Annual Meeting; May 31-June 4, 2013; Chicago, IL.

99. Brell JM, Matin K, Evans T, et al. Phase II study of docetaxel and gefitinib as second-line therapy in gemcitabine pretreated patients with advanced pancreatic cancer. Oncology. 2009;76(4):270-274.

100. Ducreux MD, I. Propper, D. et al. Exploratory serum biomarker analyses from BO21129, a phase II study of erlotinib in second line pancreatic cancer; potential role of amphiregulin. Ann Oncol. 2012;23(4):iv5-iv18.

101. Karapetis CS, Khambata-Ford S, Jonker DJ, et al. K-ras mutations and benefit from cetuximab in advanced colorectal cancer. $N$ Engl J Med. 2008;359(17):1757-1765.

102. Boeck S, Jung A, Laubender RP, et al. KRAS mutation status is not predictive for objective response to anti-EGFR treatment with erlotinib in patients with advanced pancreatic cancer. $J$ Gastroenterol. 2013; 48(4):544-548.

103. Kim ST, Lim do H, Jang KT, et al. Impact of KRAS mutations on clinical outcomes in pancreatic cancer patients treated with first-line gemcitabine-based chemotherapy. Mol Cancer Ther. 2011;10(10):1993-1999.

104. Lynch TJ, Bell DW, Sordella R, et al. Activating mutations in the epidermal growth factor receptor underlying responsiveness of non-small-cell lung cancer to gefitinib. $N$ Engl J Med. 2004;350(21): 2129-2139.

105. Kwak EL, Jankowski J, Thayer SP, et al. Epidermal growth factor receptor kinase domain mutations in esophageal and pancreatic adenocarcinomas. Clin Cancer Res. 2006;12(14 Pt 1):4283-4287.

106. Immervoll H, Hoem D, Kugarajh K, Steine SJ, Molven A. Molecular analysis of the EGFR-RAS-RAF pathway in pancreatic ductal adenocarcinomas: lack of mutations in the BRAF and EGFR genes. Virchows Arch. 2006;448(6):788-796.

107. Tzeng CW, Frolov A, Frolova N, et al. Epidermal growth factor receptor (EGFR) is highly conserved in pancreatic cancer. Surgery. 2007;141(4):464-469.

108. Li C, Iida M, Dunn EF, Ghia AJ, Wheeler DL. Nuclear EGFR contributes to acquired resistance to cetuximab. Oncogene. 2009;28(43): 3801-3813.

109. Nishimura Y, Yoshioka K, Bereczky B, Itoh K. Evidence for efficient phosphorylation of EGFR and rapid endocytosis of phosphorylated EGFR via the early/late endocytic pathway in a gefitinib-sensitive non-small cell lung cancer cell line. Mol Cancer. 2008;7:42.

110. Brand TM, Iida M, Luthar N, Starr MM, Huppert EJ, Wheeler DL. Nuclear EGFR as a molecular target in cancer. Radiother Oncol. 2013;108(3):370-377.

111. Weihua Z, Tsan R, Huang WC, et al. Survival of cancer cells is maintained by EGFR independent of its kinase activity. Cancer Cell. 2008;13(5):385-393.

112. Wheeler DL, Dunn EF, Harari PM. Understanding resistance to EGFR inhibitors-impact on future treatment strategies. Nat Rev Clin Oncol. 2010;7(9):493-507.

113. Guix M, Faber AC, Wang SE, et al. Acquired resistance to EGFR tyrosine kinase inhibitors in cancer cells is mediated by loss of IGFbinding proteins. J Clin Invest. 2008;118(7):2609-2619.

114. Ueda S, Hatsuse K, Tsuda H, et al. Potential crosstalk between insulinlike growth factor receptor type 1 and epidermal growth factor receptor in progression and metastasis of pancreatic cancer. Mod Pathol. 2006;19(6):788-796.

115. Philip PGB, Ramanathan R, Lenz H, et al. Randomized phase II trial of gemcitabine, erlotinib, and cixutumumab versus gemcitabine plus erlotinib as first-line treatment in patients with metastatic pancreatic cancer (SWOG-0727) [abstract]. J Clin Oncol. 2012; 30(4):198.
116. Bianco R, Garofalo S, Rosa R, et al. Inhibition of mTOR pathway by everolimus cooperates with EGFR inhibitors in human tumours sensitive and resistant to anti-EGFR drugs. $\mathrm{Br} J$ Cancer. 2008;98(5):923-930.

117. Kordes S, Richel DJ, Klümpen HJ, Weterman MJ, Stevens AJ, Wilmink JW. A phase I/II, non-randomized, feasibility/safety and efficacy study of the combination of everolimus, cetuximab and capecitabine in patients with advanced pancreatic cancer. Invest New Drugs. 2013;31(1):85-91.

118. Engelman JA, Zejnullahu K, Mitsudomi T, et al. MET amplification leads to gefitinib resistance in lung cancer by activating ERBB3 signaling. Science. 2007;316(5827):1039-1043.

119. Zhang YW, Staal B, Essenburg C, et al. MET kinase inhibitor SGX523 synergizes with epidermal growth factor receptor inhibitor erlotinib in a hepatocyte growth factor-dependent fashion to suppress carcinoma growth. Cancer Res. 2010;70(17):6880-6890.

120. Siena S, Sartore-Bianchi A, Di Nicolantonio F, Balfour J, Bardelli A. Biomarkers predicting clinical outcome of epidermal growth factor receptor-targeted therapy in metastatic colorectal cancer. J Natl Cancer Inst. 2009;101(19):1308-1324.

121. Schaefer G, Haber L, Crocker LM, et al. A two-in-one antibody against HER3 and EGFR has superior inhibitory activity compared with monospecific antibodies. Cancer Cell. 2011;20(4): 472-486.

122. Chong CR, Jänne PA. The quest to overcome resistance to EGFRtargeted therapies in cancer. Nat Med. 2013;19(11):1389-1400.

123. Olive KP, Jacobetz MA, Davidson CJ, et al. Inhibition of Hedgehog signaling enhances delivery of chemotherapy in a mouse model of pancreatic cancer. Science. 2009;324(5933):1457-1461.

124. López R, Méndez CM, Fernández MJ, et al. Phase II trial of erlotinib plus capecitabine as first-line treatment for metastatic pancreatic cancer (XELTA study). Anticancer Res. 2013;33(2):717-723.

125. Hwang IG, Jang JS, Oh SY, et al. A phase II trial of Erlotinib in combination with gemcitabine and cisplatin in advanced pancreatic cancer. Invest New Drugs. 2012;30(6):2371-2376.

126. Oh DY, Lee KW, Lee KH, et al. A phase II trial of erlotinib in combination with gemcitabine and capecitabine in previously untreated metastatic/recurrent pancreatic cancer: combined analysis with translational research. Invest New Drugs. 2012;30(3):1164-1174.

127. Merchan JR, Ferrell A, Macintyre J, et al. Phase II study of gemcitabine, oxaliplatin, and cetuximab in advanced pancreatic cancer. Am J Clin Oncol. 2012;35(5):446-450.

128. Crane CH, Varadhachary GR, Yordy JS, et al. Phase II trial of cetuximab, gemcitabine, and oxaliplatin followed by chemoradiation with cetuximab for locally advanced (T4) pancreatic adenocarcinoma: correlation of Smad4(Dpc4) immunostaining with pattern of disease progression. J Clin Oncol. 2011;29(22):3037-3043.

129. Feliu J, Borrega P, León A, et al. Phase II study of a fixed dose-rate infusion of gemcitabine associated with erlotinib in advanced pancreatic cancer. Cancer Chemother Pharmacol. 2011;67(1):215-221.

130. El-Rayes BF, Philip PA, Sarkar FH, et al. A phase II study of isoflavones, erlotinib, and gemcitabine in advanced pancreatic cancer. Invest New Drugs. 2011;29(4):694-699.

131. Kullmann F, Hollerbach S, Dollinger MM, et al. Cetuximab plus gemcitabine/oxaliplatin (GEMOXCET) in first-line metastatic pancreatic cancer: a multicentre phase II study. Br J Cancer. 2009;100(7): 1032-1036.

132. Fountzilas G, Bobos M, Kalogera-Fountzila A, et al. Gemcitabine combined with gefitinib in patients with inoperable or metastatic pancreatic cancer: a phase II Study of the Hellenic Cooperative Oncology Group with biomarker evaluation. Cancer Invest. 2008;26(8):784-793.

133. Ignatiadis M, Polyzos A, Stathopoulos GP, et al. A multicenter phase II study of docetaxel in combination with gefitinib in gemcitabinepretreated patients with advanced/metastatic pancreatic cancer. Oncology. 2006;71(3-4):159-163. 


\section{Publish your work in this journal}

Gastrointestinal Cancer: Targets and Therapy is an international, peer-reviewed, open access journal focusing on gastro-intestinal cancer research, identification of therapeutic targets and the optimal use of preventative and integrated treatment interventions to achieve improved outcomes, enhanced survival and quality of life for the cancer patient. The manuscript management system is completely online and includes a very quick and fair peer-review system. Visit http://www.dovepress.com/testimonials.php to read real quotes from published authors.

Submit your manuscript here: http://www.dovepress.com/gastro-intestinal-cancer-targets-and-therapy-journal 